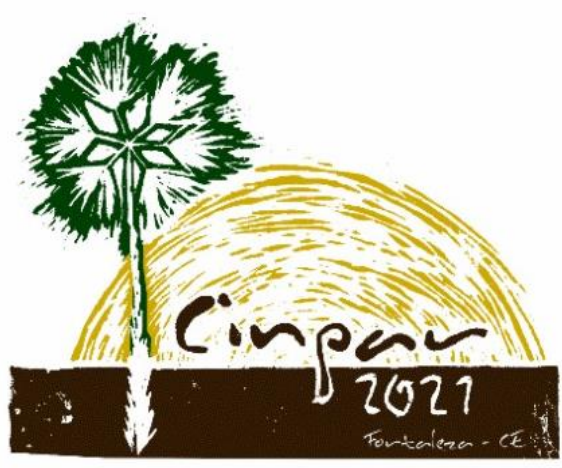

XVII Congresso Internacional sobre Patologia e

Reabilitação das Construções

XVII Congreso Internacional sobre Patología y Rehabilitación de las Construcciones

XVII International Conference on Pathology and Constructions Rehabilitation

FORTALEZA (Brasil), 3 a 5 de junho de 2021

https://doi.org/10.4322/CINPAR.2021.082

\title{
Avaliação de Tratamentos Superficiais de Rodovias Através de Ensaios Laboratoriais
}

\section{Evaluation of Surface Treatments of Roads Through Laboratory Tests}

\author{
Synardo L. O. PEREIRA ${ }^{1}$, Suelly H. A. BARROSO ${ }^{2}$, Miguel A. G. CIRINO ${ }^{3}$, Bruno B. OLIVEIRA ${ }^{4}$ \\ ${ }^{1}$ Universidade Regional do Cariri - URCA, Ceará, Brasil, synardo.pereira@urca.br \\ ${ }^{2}$ Universidade Federal do Ceará - UFC, Ceará, Brasil, suelly@det.ufc.br \\ ${ }^{3}$ Universidade Regional do Cariri - URCA, Ceará, Brasil, miguel.goncalves@urca.br \\ ${ }^{4}$ Universidade Regional do Cariri - URCA, Ceará, Brasil, bruno.barbosa@urca.br
}

\begin{abstract}
Resumo: Os pavimentos são definidos como estruturas de múltiplas camadas, construídas sobre a superfície final de terraplenagem, a fim de resistir aos esforços aplicados pelo tráfego e do clima, garantindo conforto, economia e segurança aos usuários. Podem ser classificados em pavimentos rígidos, em que a capa de rolamento final ou revestimento é uma placa de concreto de cimento Portland e pavimentos flexíveis, quando o revestimento é composto de uma mistura asfáltica, constituída basicamente de agregados e ligantes betuminosos. Dentre os revestimentos asfálticos utilizados destaca-se o Tratamento Superficial (TS), revestimento delgado, de pequena espessura e custo reduzido, constituído pelo espalhamento de ligante betuminoso e agregado mineral, com posterior compactação. No Estado do Ceará, nordeste brasileiro, representa cerca de $61 \%$ da malha rodoviária pavimentada estadual. Apesar de sua grande utilização, não existem métodos atuais de dosagem ou processo para avaliação de desempenho em laboratório, o que pode acarretar no surgimento de vários tipos de defeitos nas rodovias. O presente trabalho busca avaliar o desempenho do TS em laboratorio através do desgaste sofrido pelos corpos de prova submetidos ao ensaio Wet Track Abrasion Test (WTAT), equipamento utilizado para dosagem de microrrevestimento asfáltico e adaptado neste trabalho para avaliação do TS. Espera-se, à luz dos resultados obtidos, classificar as melhores dosagens de agregados e ligantes. Por fim, espera-se ainda comprovar a eficácia do ensaio WTAT, que pode ser uma ótima ferramenta para avaliação dos tratamentos superficiais, além de ser um equipamento de baixo custo, podendo ser adquirido pela maioria dos laboratórios.
\end{abstract}

Palavras-chave: tratamento superficial, avaliação de desempenho, WTAT.

Abstract: Pavements are defined as multi-layered structures, built on the final earthwork surface, in order to resist the efforts applied by traffic and the weather, ensuring comfort, economy and safety for users. They can be classified as rigid pavements, where the final bearing cover or coating is a Portland cement concrete slab and flexible pavements, when the coating is composed of an asphalt mixture, consisting basically of bituminous aggregates and binders. Among the asphalt coatings used, the Asphalt Surface Treatment (AST) stands out, thin, thin and low cost coating, consisting of the spreading of bituminous binder and mineral aggregate, with subsequent compaction. In the state of Ceará, northeastern Brazil, it represents about $61 \%$ of the state's paved road network. Despite its widespread use, there are no current dosage methods or processes for evaluating laboratory performance, which can result in the emergence of various types of defects on the highways. The present work seeks to evaluate the performance of the AST in the laboratory through the wear suffered by the specimens submitted to the Wet Track Abrasion Test 
(WTAT), equipment used to measure asphalt micro-coating and adapted in this work to evaluate the AST. It is expected, in the light of the results obtained, to classify the best dosages of aggregates and binders. Finally, it is also expected to prove the effectiveness of the WTAT test, which can be a great tool for evaluating surface treatments, in addition to being a low-cost equipment, which can be purchased by most laboratories.

Keywords: surface treatment, performance evaluation, WTAT.

\section{Introdução}

Os pavimentos são estruturas formadas por múltiplas camadas, onde o chamado revestimento é a camada mais superficial e que tem por função receber a carga dos veículos e mais diretamente a ação climática. É necessário que essa camada seja tanto quanto possível impermeável e resistente aos esforços de contato pneu-pavimento. Esses esforços são variados conforme a configuração das cargas e a velocidade dos veículos. Para tanto, os pavimentos são classificados, em geral, de acordo com a forma de distribuição dos esforços gerados pelo tráfego ao longo das camadas do pavimento, em rígidos e flexíveis.

Os pavimentos rígidos são compostos por uma camada superficial de concreto de cimento Portland, construída sobre uma camada de material granular ou de material estabilizado com cimento (chamada subbase), assentada sobre o subleito ou sobre um reforço do subleito quando necessário. Os pavimentos flexíveis são compostos por revestimento de material asfáltico, apoiado sobre camadas (geralmente base, sub-base e reforço do subleito) constituídas por materiais granulares (solos ou misturas de solos, com ou sem adição de agentes estabilizantes) (DNIT, 2005)

Dentre os diversos tipos de revestimentos asfálticos destacam-se os tratamentos superficiais (TS), que consistem na aplicação de ligante asfáltico e agregado em camadas simples ou múltiplas, com posterior compactação. $O$ tratamento superficial se apresenta ainda como uma ótima solução para rodovias de Baixo Volume de Tráfego (RBVT). Segundo o Informativo Gerencial do Departamento Estadual de Rodovias (DERpCE, 2017), Para o estado do Ceará, no nordeste brasileiro, o TS constitui cerca de $64 \%$ de toda a malha estadual pavimentada. Essa realidade não difere do restante dos estados brasileiros, principalmente daqueles pertencentes à região Nordeste.

Apesar de ser bastante utilizado observa-se que ainda são poucos os estudos laboratoriais de dosagem e avaliação das melhores taxas de aplicação dos materiais para TS, sendo essas taxas muitas vezes aplicadas de acordo com as normas rodoviárias (às vezes inadequadas), guiadas pelo bom senso do profissional. Essa prática pode provocar a ocorrência de defeitos no pavimento executado, além do aumento dos custos de construção e/ou manutenção. Assim, o objetivo do presente trabalho é avaliar o desempenho de amostras de TS construídas através de um procedimento laboratorial.

\section{Revisão da Literatura}

O tratamento superficial é definindo-o com um revestimento executado através de uma ou mais aplicações de ligante betuminoso, seguido de igual número de operações de espalhamento e compactação de camadas de agregados com granulometria apropriadas [10]. Pode ser classificado como tratamento superficial simples (TSS), duplo (TSD) ou triplo (TST), dependendo do número de aplicações de ligante e agregado (DNIT, 2006), conforme ilustração apresentada na Figura 1.

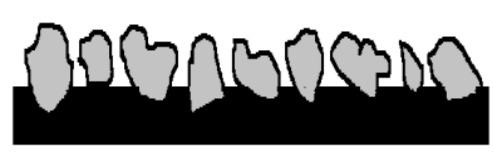

TSS;

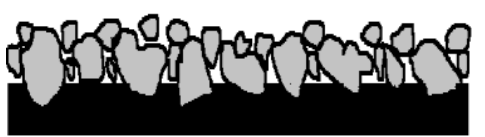

TSD;

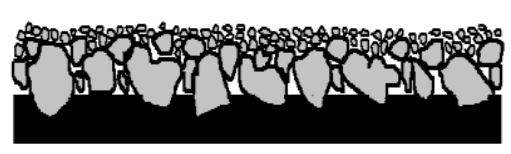

TST

Figura 1 - Classificação dos tratamentos superficiais 
Segundo Melo (1978), Larsen (1985) e Bernucci et al. (2010), as principais funções do tratamento superficial são:

- primeiro revestimento de pavimentos sujeitos a tráfego leve ou médio;

- camada de rolamento de pequena espessura, porém, de alta resistência contra desgaste;

- impermeabilizar, ou rejuvenescer revestimentos asfálticos envelhecidos, fissurados e sujeitos à infiltração de água;

- proteger a infraestrutura do pavimento;

- revestimento anti-derrapante, melhorando a resistência ao deslizamento;

- aumentar a resistência ao desgaste do revestimento;

- revestimento de alta flexibilidade, onde o trincamento por fadiga é quase inexistente;

- alta refletância e alta aderência entre pneu e superfície;

- sinalização visual, ao se utilizar agregados de cores diferentes;

- revestimento da primeira etapa da construção definitiva de pavimentos sujeitos a tráfego médio ou pesado.

A execução dos tratamentos superficiais envolve os seguintes equipamentos principais: caminhão espargidor de ligante, equipamento mais importante para a execução do TS, composto de vários dispositivos como tanque de armazenamento, sistema de aquecimento e barra de distribuição de ligante; distribuidor de agregado, com espalhamento do material na taxa definida em projeto e rolos compactadores (lisos e pneumáticos) para a acomodação dos agregados, conforme apresentado na Figura 2.

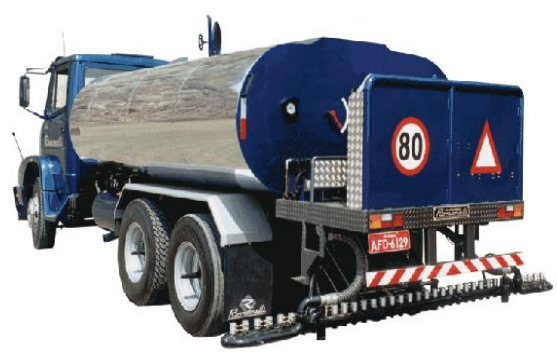

a) espargidor de ligante;

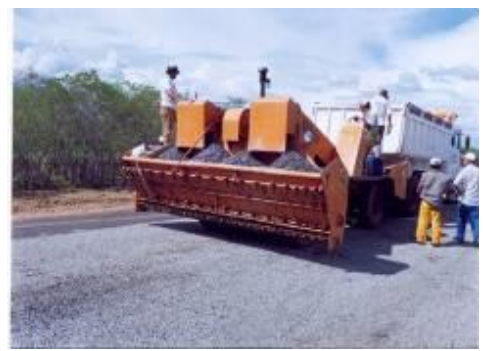

b) distribuidor de agregado;

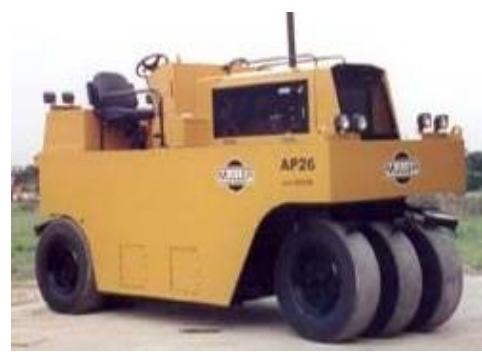

c) rolo de pneus

Figura 2 - Equipamentos utilizados na execução dos tratamentos superficiais

\section{Materiais e Métodos}

Foram selecionados dois tipos de agregados minerais de pedreiras distintas que geralmente comercializam materiais para obras de construção civil na Região Metropolitana de Fortaleza. Como ligante asfáltico, foram selecionadas a emulsão asfáltica convencional (RR-2C) e a emulsão asfáltica modificada por polímero (RR2C-E). Atualmente utiliza-se a emulsão asfáltica convencional para serviços de tratamentos superficiais, apesar das diversas vantagens da emulsão modificada por polímero.

Após determinadas as taxas de agregados e ligantes foram construídas 9 mantas de revestimentos do tipo TSD para cada material testado. Para tanto, utilizou-se um procedimento para confecção de revestimentos de tratamento superficial em laboratório desenvolvido por Loiola (2009), posteriormente modificado em sua forma de compactação das mantas (PEREIRA, 2010) e na maneira de distribuição dos agregados (PEREIRA, 2013). Esse procedimento visa simular todas as etapas construtivas de um serviço de tratamento superficial executado em campo. Sobre uma manta asfáltica de $3 \mathrm{~mm}$ (vendida em rolos e utilizada em serviços de imprimação de lajes e caixas d'águas), cortada em tamanho adequado em formato circular e delimitadas por um aro metálico com $28 \mathrm{~cm}$ de diâmetro interno, foram aplicados o ligante betuminoso e os agregados nas quantidades previamente calculadas para cada tipo de agregado. A cada aplicação de ligante 
e agregado o conjunto foi compactado e ao final do processo aplicou-se um banho diluído de emulsão+água na proporção (1:1).

Ao final, as mantas de TSD, foram submetidas ao ensaio Wet Track Abrasion Test (WTAT) para avaliação do desgaste do revestimento. A Figura 3 apresenta as etapas do processo construtivo das mantas de TSD em laboratório. Ressalta-se que o TSD consiste em duas aplicações de ligantes, alternadas por duas camadas de agregados.

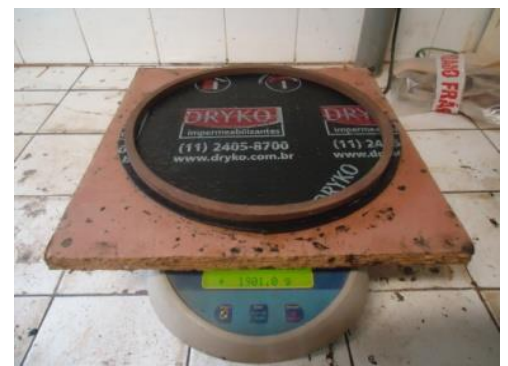

manta e molde metálico;

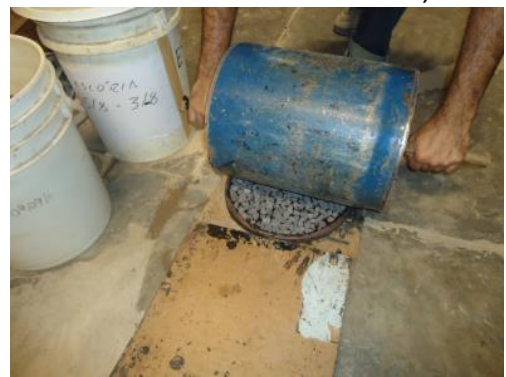

compactação da 1ạ camada;

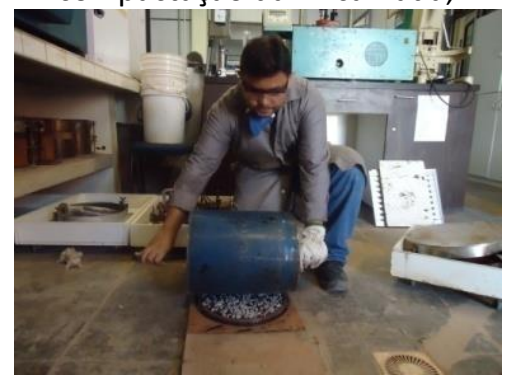

compactação da 2aㅡ camada;

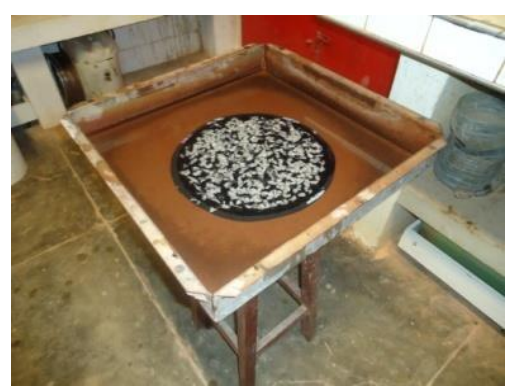

imersão do revestimento;

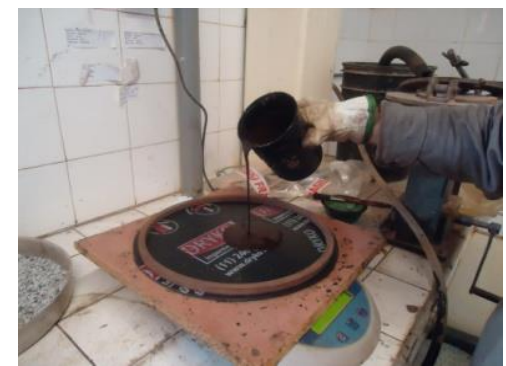

aplicação da 1a tx de ligante;

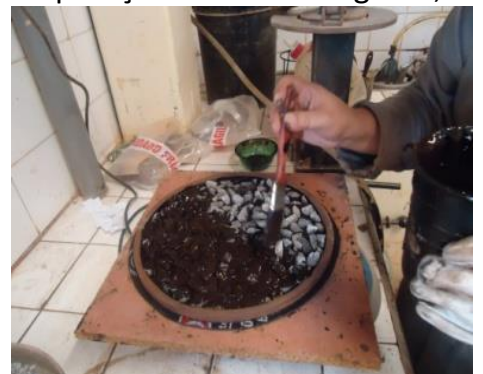

aplicação da 2a tx de ligante;

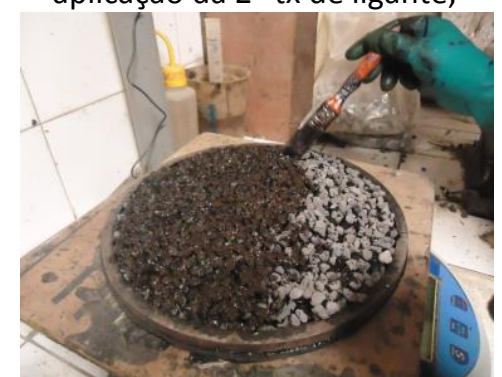

aplicação do banho diluído;

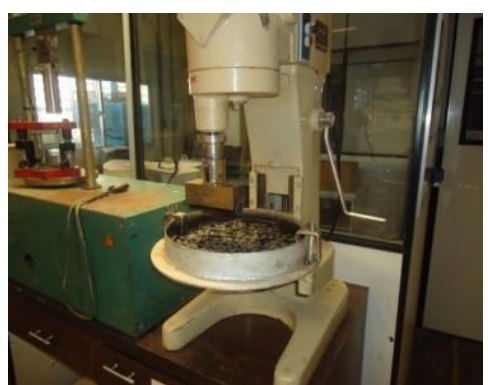

ensaio WTAT (abrasão);

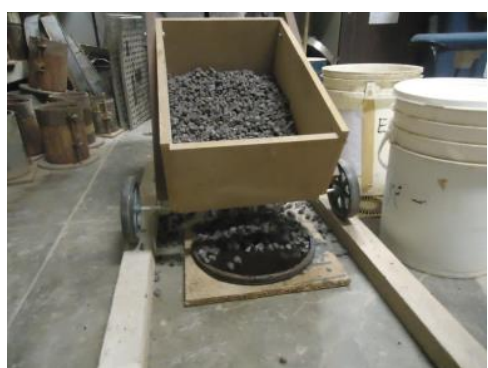

aplicação da 1ạ tx de agregado;

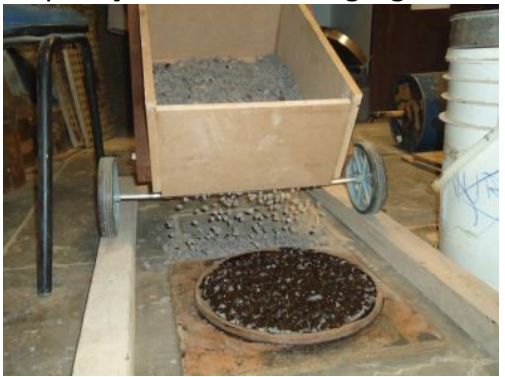

aplicação da 2a tx de agregado;

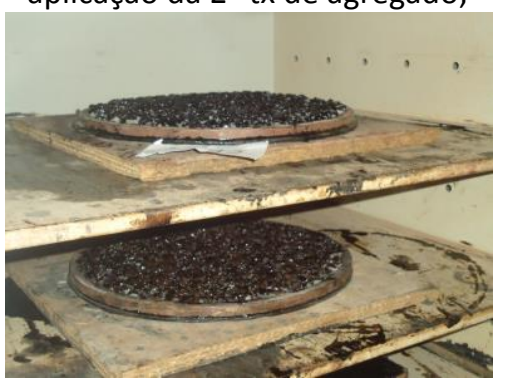

secagem em estufa;

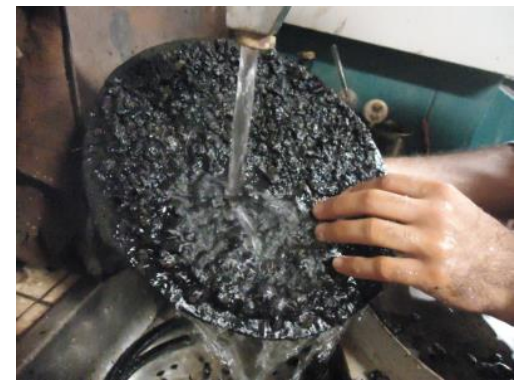

lavagem após ensaio.

Figura 3 - Processo construtivo do TSD em laboratório

O procedimento de construção das mantas de TSD consta das seguintes etapas:

1. pesa-se o conjunto (bandeja, placa de zinco, manta asfáltica anel metálico);

2. aplicação da 1a taxa do ligante asfáltico a fim de atingir o valor calculado;

3. aplicação da 1ạ camada de agregado (graúdo); 
4. submete-se o conjunto ao processo de compactação;

5. aplicação da 2 a taxa de ligante;

6. aplicação da 2a camada de agregado (miúdo);

7. nova compactação do conjunto;

8. aplicação do banho diluído (mistura de água e emulsão na proporção de 1:1);

9. secagem da manta em estufa a $60 \circ \mathrm{C}$ por $24 \mathrm{~h}$;

10. retirada da manta da estufa e após o esfriamento pesagem antes do ensaio (P1);

11. submersão em água por 10 minutos e ensaio no equipamento WTAT por 5 minutos;

12. lavagem da manta para retirada de partículas soltas e em estufa a $600 \mathrm{C}$ até constância do peso;

13. após retirada da estufa e esfriamento faz-se a pesagem da manta (P2);

14. cálculo do desgaste (D), em \%, através da diferença de pesos, conforme a equação (1):

$$
D=\frac{P 1-P 2}{P 1} \times 100
$$

O ensaio Wet Track Abrasion Test (WTAT) consta na norma técnica da ABNT NBR 14746: "Microrevestimento a frio e lama asfáltica - determinação de perda por abrasão úmida (WTAT)". O ensaio determina a resistência à abrasão sob ação simulada da água e do tráfego e o teor mínimo de ligante residual do MRAF através do desgaste do revestimento por diferença de massa (CERATTI, 2011). Assim como foi feita uma adaptação do equipamento para avaliação de tratamentos superficiais, alguns autores já adaptaram tal equipamento para outros fins: tratamento antipó (DUQUE NETO, 2004) e avaliação de camadas de solo-emulsão (GONDIM, 2008).

\section{Apresentação dos Resultados}

Foi realizada a caracterização dos agregados para verificação se os mesmos atendiam aos requisitos estabelecidos nas especificações técnicas, quanto à granulometria, abrasão Los Angeles, índice de forma, durabilidade, absorção e densidade e adesividade ao ligante.

Quanto aos ligantes asfálticos, os mesmos foram fornecidos com a certificação das empresas que produzem e comercializam os mesmos. Após a caracterização verificou-se que os agregados atendiam todos os quesitos propostos para aplicação em pavimentação.

Após a caracterização foram determinadas as dosagens dos agregados e ligantes conforme método utilizado pelo DER-CE (DERT-CE ES-P 11/00). Tais taxas constam no Quadro 1 a seguir:

Quadro 1 - Taxas de ligante e agregado.

\begin{tabular}{|c|c|c|c|c|c|c|c|}
\hline Agr & $\begin{array}{l}\text { 1a tx de } \\
\text { ligante } \\
(1 / m 2)\end{array}$ & $\begin{array}{c}\text { 1a tx de } \\
\text { agregado } \\
(\mathrm{kg} / \mathrm{m} 2)\end{array}$ & $\begin{array}{l}2^{\mathrm{a}} \text { tx de } \\
\text { ligante } \\
(\mathrm{I} / \mathrm{m} 2)\end{array}$ & $\begin{array}{c}2^{a} \text { tx de } \\
\text { agregado } \\
(\mathrm{kg} / \mathrm{m} 2)\end{array}$ & $\begin{array}{l}\text { Banho } \\
\text { diluído } \\
(1 / \mathrm{m} 2)\end{array}$ & $\begin{array}{c}\text { Taxa total } \\
\text { de ligante } \\
(1 / \mathrm{m} 2)\end{array}$ & $\begin{array}{l}\text { Taxa total } \\
\text { de agreg. } \\
(\mathrm{kg} / \mathrm{m} 2)\end{array}$ \\
\hline Agreg. 1 & 1,04 & 14,39 & 1,07 & 8,19 & 0,50 & 2,61 & 22,58 \\
\hline Agreg. 2 & 0,64 & 13,82 & 0,50 & 5,32 & 0,45 & 1,59 & 19,14 \\
\hline
\end{tabular}

Em seguida foram confeccionados 9 corpos de provas de TSD, nesse trabalho denominadas de mantas de TSD, conforme procedimento de execução em laboratório apresentado anteriormente, para cada um dos materiais estudados (agregados 1 e 2; emulsão convencional e emulsão modificada por polímero), totalizando 36 mantas. 
De um modo geral, observou-se que as taxas totais de ligante foram levemente maiores que as taxas de projeto, enquanto as taxas de agregados foram levemente menores, para o caso da emulsão convencional. Para a emulsão modificada por polímero observou-se taxas menores tanto para os ligantes quantos para os agregados. Isso já era esperado, uma vez que uma das vantagens da emulsão modificada por polímeros é justamente a necessidade de uma menor quantidade de ligante para envolver todo o agregado.

As Figuras 4 e 5 apresentam as taxas de ligantes e agregados utilizando as emulsões convencional e modificada por polímero, respectivamente. As Figuras 6 e 7 apresentam os desgastes médios sofridos pelas mantas ao serem submetidas ao ensaio WTAT.
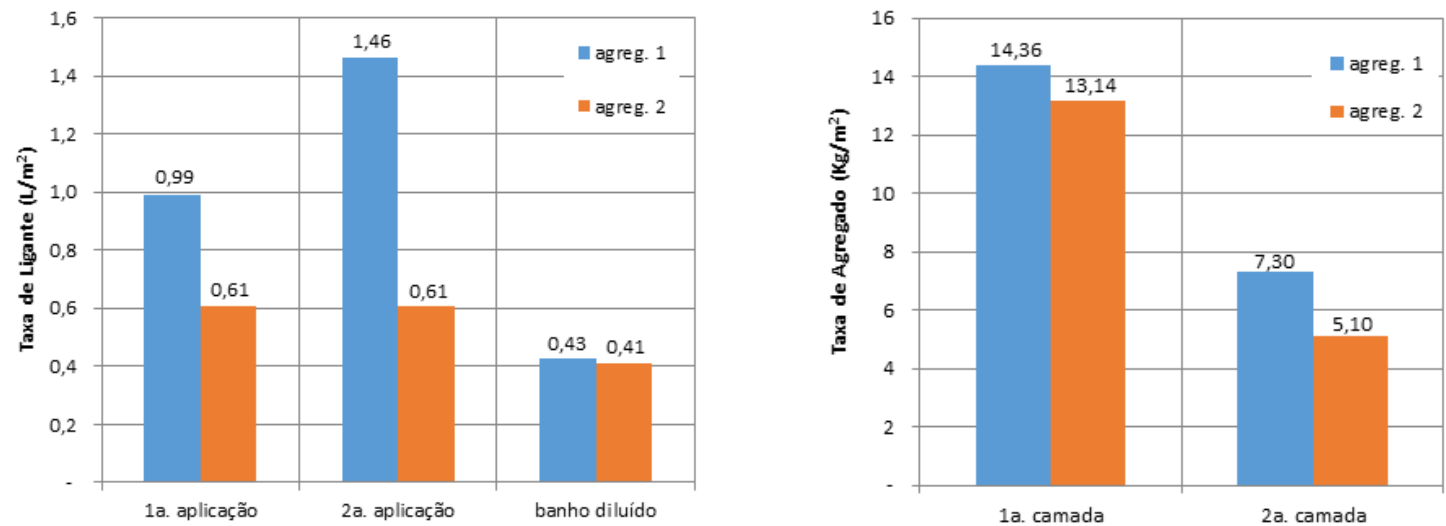

Figura 4 - Taxas de materiais de TSD com emulsão RR-2C
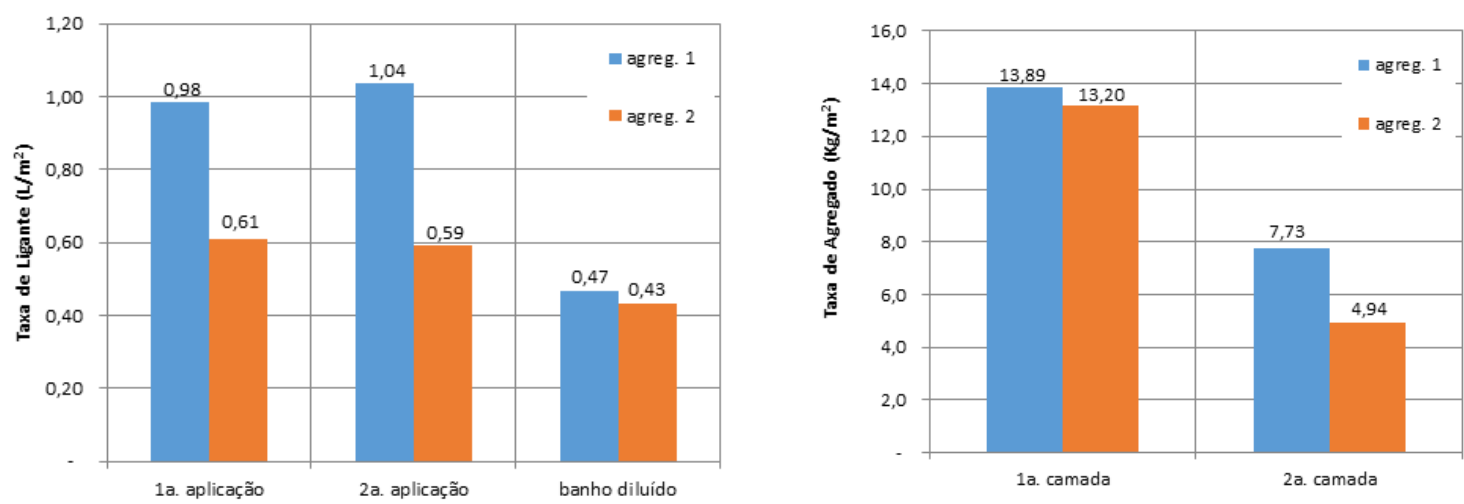

Figura 5 - Taxas de materiais de TSD com emulsão RR2C-E

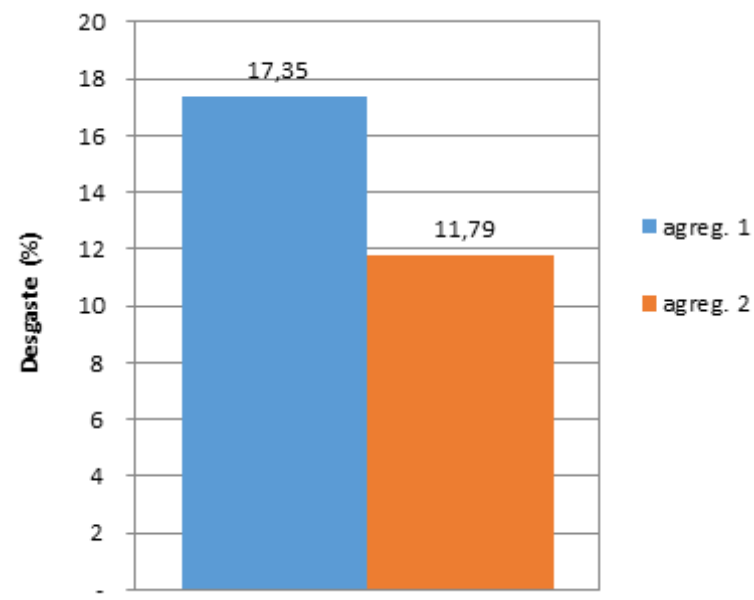

Figura 6 - Desgaste das mantas com emulsão RR-2C através do ensaio WTAT

Avaliação de Tratamentos Superficiais de Rodovias Através de Ensaios Laboratoriais 


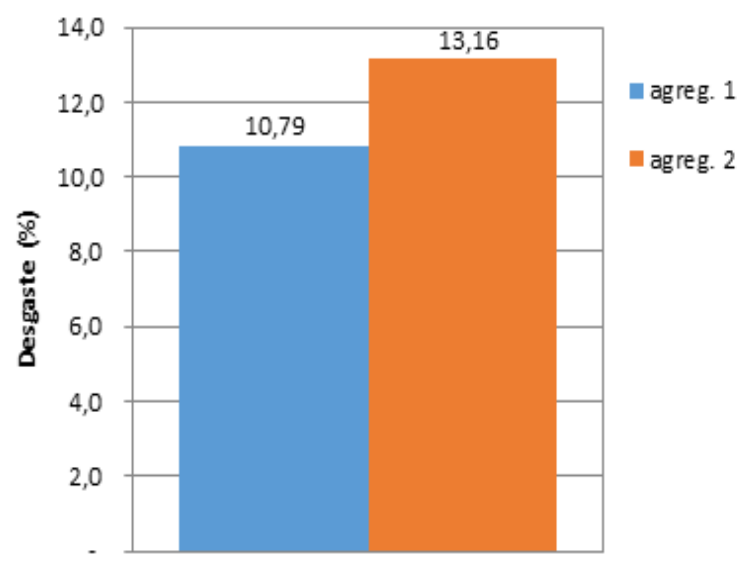

Figura 7 - Desgaste das mantas com emulsão RR2C-E através do ensaio WTAT

Através das Figuras 6 e 7 percebe-se que o agregado 1 obtive menor desgaste com o uso da emulsão modificada por polímero. Não foi observado melhora no comportamento para o agregado 2, apresentando valores de desgaste levemente superior para o caso da emulsão modificada. Assim, observa-se que em termos absolutos a utilização da emulsão modificada por polímeros não trouxe maiores benefícios para o desempenho dos revestimentos de TSD, quando considerado o ensaio WTAT.

A comparação entre os desgastes sofridos para os dois tipos de emulsão teve como intenção observar se haveria alguma melhora no comportamento do revestimento com a utilização da emulsão modificada por polímero. Considera-se, nesse estudo, que um menor desgaste no ensaio WTAT pode significar que o ligante obteve um poder maior de segurar o agregado, impedindo que o mesmo fosse arrancado durante o ensaio, garantindo um melhor desempenho do revestimento. Em campo isso pode representar um revestimento de melhor qualidade, com uma vida útil maior e serviços de manutenção mais espaçados durante o tempo.

\section{Conclusões}

Conclui-se através dos resultados dos ensaios realizados que o agregado 2 apresentou os menores desgastes $(11,79 \%)$ em comparação com o agregado 1 (17,35\%). Já para o caso do TSD com RR2C-E, o agregado 1 obteve o menor desgaste (10,79\%), enquanto o agregado 2 apresentou um desgaste um pouco maior (13,16\%). Ao se comparar os desempenhos dos revestimentos com o uso dos dois tipos de ligantes, observou-se que houve apenas uma pequena melhora nos desempenhos dos agregados 1 , enquanto que $o$ agregado 2 apresentou um menor desempenho para o uso da emulsão modificada. Assim, à luz da realização dos ensaios de WTAT, percebeu-se que a utilização da emulsão RR2C-E não trouxe grandes benefícios para os revestimentos de TSD.

No entanto, sabe-se que esse ensaio, originalmente desenvolvido para microrrevestimento asfáltico e adaptado para o caso em estudo, se dá de uma maneira muito agressiva nos revestimentos de tratamento superficial, sendo necessários mais estudos para aprimorar o uso deste equipamento, que pode ser facilmente encontrado nos laboratórios de pavimentação devido o seu valor acessível. Por fim, entende-se que o mesmo se mostra uma ótima ferramenta para avaliação de desempenho dos tratamentos superficiais em laboratório. 


\section{Agradecimentos}

Agradecimentos ao Laboratório de Mecânica de Pavimentos (LMP) da Universidade Federal do Ceará, Asfaltos Nordestes pelas emulsões asfálticas e pedreiras da Região Metropolitana de Fortaleza pelos agregados cedidos.

\section{Referências Bibliográficas}

Associação Brasileira De Normas Técnicas - ABNT. NBR 14746 (2001). Microrrevestimentos a frio e lama asfáltica - Determinação de perda por abrasão úmida (WTAT). Rio de Janeiro.

Bernucci, L. B., Motta, L. M. G., Ceratti, J. A. P., Soares, J. B. Pavimentação Asfáltica. Formação Básica para Engenheiros. 3a. Reimpressão. PETOBRAS. ABEDA. Rio de Janeiro, 2010.

Ceratti, J. A. P.; Reis, R. M. M. (2011). Manual de Microrrevestimento Asfáltico a Frio. Rio de Janeiro: Oficina de Textos, Instituto Pavimentar.

Departamento de Edificações, Rodovias e Transportes - DERT-CE. ES-P 11/00 (2000). Tratamento Superficial Duplo. Especificações gerais para serviços e obras rodoviárias. Pavimentação. Fortaleza, Ceará.

Departamento Estadual de Rodovias - DER-CE. (2017). Informativo Gerencial 2017 (Edição Comemorativa). Fortaleza, Ceará.

Departamento Nacional de Infraestrutura de Transportes - DNIT (2005). Manual de Pavimentos Rígidos. Publicação IPR - 714. Rio de Janeiro.

Departamento Nacional de Infraestrutura de Transportes - DNIT. (2006). Manual de Pavimentação. Publicação IPR - 719. Rio de Janeiro.

Duque Neto, F. S. (2004). Proposição de Metodologia para a Escolha de Solo e Dosagem de Antipó com Emulsão de Xisto. Dissertação de Mestrado em Engenharia Civil, COPPE/UFRJ, Rio de Janeiro, RJ.

Gondim, L. M. (2008). Estudo Experimental de Misturas Solo-Emulsão Aplicado às Rodovias do Agropólo do Baixo Jaguaribe. Dissertação de Mestrado. Universidade Federal do Ceará - UFC. Fortaleza, Ceará,

Larsen, J. (1985). Tratamento Superficial na Conservação e Construção de Rodovias. Abeda. Rio de Janeiro.

Loiola, P. R. R. (2009). Estudo de Agregados e Ligantes Alternativos para Emprego em Tratamentos Superficiais de Rodovias. Dissertação de Mestrado. Universidade Federal do Ceará - UFC. Fortaleza, Ceará.

Melo, A. L. (1978). Tratamentos Superficiais. Universidade Federal de Pernambuco. Centro de Tecnologia. Instituto de Pesquisas Rodoviárias. Recife, Pernambuco.

Pereira, S. L. O. (2010). Avaliação de Tratamentos Superficiais de Rodovias Através de Análise de Laboratório. Projeto de Graduação. Curso de Engenharia Civil. Universidade Federal do Ceará - UFC. Fortaleza, Ceará.

Pereira, S. L. O. (2013). Avaliação dos Tratamentos Superficiais Simples, Duplo e Triplo de Rodovias Através do Emprego de Diferentes Agregados da Região Metropolitana de Fortaleza. Dissertação de Mestrado. Universidade Federal do Ceará - UFC. Fortaleza, Ceará. 